\title{
MELHORADO GENETICAMENTE, PATENTEADO E AMEAÇADO: CUIDADO DE SI E DIGNIDADE HUMANA EM TEMPOS BIOTECNOLÓGICOS
}

Marcelo Pelizzoli* Erliane Miranda**

RESUMO - Trata-se de uma reflexão sobre as ameaças aos direitos humanos, sobretudo à dignidade e à liberdade, e à essência humana geradas pelo avanço da biotecnologia. $\mathrm{O}$ foco de alerta e resgate da noção de cuidado de si perpassa a perspectiva de futuro de M. Foucault e usa como complemento e desfecho a noção de responsabilidade de H. Jonas para a manutenção da vida e para a realização do sentido do humano e das novas gerações - papel ético por excelência. O texto divide-se em duas partes: a primeira é inspirada em Foucault e a segunda, em Jonas. O leitor é convidado a refletir dentro de uma dupla consideração do tema.

PALAVRAS-CHAVE - Dignidade. Direitos humanos. Cuidado de si. Responsabilidade. Futuro. M. Foucault. H. Jonas.

\begin{abstract}
It concerns a reflection on threats to human rights, above all to dignity and liberty, and to human essence generated by the development of bioechnology. The focus and the rescue of the notion of taking care of oneself surpass $M$. Foucault's understanding of future and use $\mathrm{H}$. Jonas' notion of responsibility as complement and conclusion to the maintenance of life and to the accomplishment of the sense of humankind and new generation - main roles of ethics. The text is separated in two parts: the first one is inspired in Foucault and the second one is inspired in Jonas. The reader is invited to consider these two views of the theme

KEY WORDS - Dignity. Human rights. Taking care of oneself. Responsibility. Future.
\end{abstract}

\section{Do animal humano ao agregado genético patenteado?}

"Conseguimos artificialmente torná-los mais fortes e mais altos que o normal da espécie e também o contrário. Fazemo-los mais fecundos e prolíferos que o normal, ou ao contrário, estéreis e infecundos. Podemos mudar-lhes a cor, a forma, a atividade, de muitas maneiras."

(F. BACON, New Atlantis, 1627)

* Doutor em Filosofia pela PUCRS, Professor do Programa de Pós-Graduação em Filosofia da UFPE. opelicano@ig.com.br

** Especialista em Bioética e Saúde; Mestre em Sociologia - UFPE.

\begin{tabular}{|l|l|l|l|l|l|} 
VERITAS & Porto Alegre & v. 53 & n. 2 & abr./jun. 2008 & p. 73-89
\end{tabular}


Muito do desenvolvimento tecnocientífico está hoje acoplado a uma "Nova Era": a da Biotecnologia, onde confluem informática, biologia, nanotecnologia e outros campos, abrindo - supostamente - possibilidades ilimitadas de pesquisa e de intervenção na dinâmica dos seres vivos. As mudanças e novidades são surpreendentes, e deslumbram as sociedades, ou melhor, àquela fatia que delas pode se beneficiar, e conferir-lhe sentido e valor. Hoje, por exemplo, à bagatela de $R \$$ 1.000,00 (mil reais) mensais, pode-se manter congelado um embrião para que se garanta a "autonomia" de qualquer indivíduo sobre a perpetuação de sua linhagem à revelia dos limites, desprezivelmente finitos, que lhes são característicos em função de sua pertença à espécie humana. Aos críticos de tal investimento na manutenção de um "projeto" de vida ser mantido ao mesmo custo mensal de, em média, quatro cestas básicas que poderiam alimentar quatro famílias "vivas", caberia (e porque não?) ao eventual investidor de tal façanha a reivindicação de seus direitos humanos de "patente"! Sim, patente. Se, passamos a ser, em tese, um alfabeto genético inventariável, e "Toda pessoa tem direito à proteção dos interesses morais e materiais decorrentes de qualquer produção científica, literária ou artística da qual seja autor"1, ora, direitos humanos são hoje direitos também autorais. Direitos à perpetuação da espécie são, hoje, também "royalties": “O 'humano' não é um conceito politicamente ingênuo, fato que pode ser confirmado se nos debruçarmos sobre aquilo que ele exclui de seu campo civilizador. Na história do ocidente, uma área fundamental de exclusão é precisamente o mundo natural"2.

Não cremos no mito pós-moderno do homem-informação do tipo objeto, ainda que consideremos que o indivíduo contemporâneo se valha de tal imagem por esta lhe figurar produtiva e conveniente dentro dos moldes do paradigma vigente e lhe conferir um status de portador de uma capacidade "plástica". No entanto, apesar, ou justamente por isso, daí nos ocorre uma dúvida sobre outra dimensão da ingenuidade desse mesmo indivíduo: a lúdica, ou mais precisamente, àquela na qual ele aposta na capacidade de uma simulação, ou, mesmo, de uma transmutação de si, fundamentada no discurso de uma integração do ser vivo, enquanto real, com o universo virtual ser tão possível como inevitável. É, pois, daí que suspeitamos de uma imaturidade, ou de uma ausência de exercício de si - de sua própria abstração, que concorre na crença de sua desnaturalização de homemhumano e incorre, diretamente, na formação de modelos ideológicos antisingularidade e, portanto, anti-alteridade. Estes, potencialmente perigosos, haja vista as experiências da nossa civilização às semelhantes formações ideologicamente modais terem resultado no "desprezo e [n]o desrespeito

Declaração Universal dos Direitos do Homem, Artigo XXVII/3.

2 Cf. FERREIRA: 2003; p. 221. 
pelos direitos humanos [que] resultaram em atos bárbaros que ultrajaram a consciência da Humanidade" - e aqui nos reportamos ao evento que justificou a elaboração da Declaração Universal dos Direitos Humanos pela Assembléia Geral das Nações Unidas em 10 de dezembro de 1948, o holocausto.

Hoje, preocupa-nos a sensação dessa ausência de demarcação, ou essa fluidez em que vemos o homem burguês urbano perder-se em engenhosidades pretensamente suas; preocupa-nos, igualmente, a impressão de um velamento de qualquer distinção entre suas dimensões real e virtual, natural e artificial, bem como de um critério de hierarquia, ou referência, sobre suas crenças individuais ou coletivas, porque tememos uma nova modalidade de perda de autonomia responsável, que parece ser fomentada aos poucos, sob a égide de mitologias tecnocientíficas, a partir de uma perda ou confusão de identidades ${ }^{3}$.

A própria idéia de terapia gênica - mas também as novas formas de reprodução humana - penetrando espaços inclusive de ordem emocional e cultural do sujeito, abre um campo de ambigüidades na relação ser humano e natureza, animal-humano e cultura, em direção às inquietudes da dromologia - velocidade da tecnologia "a todo custo". Devemos perguntar aí: quais as motivações? O Bem humano, ou o acúmulo de bens por parte dos detentores das tecnologias e novas drogas? Junte-se a isso a idéia de um inventário informacional - genético e neurológico - acessando pretensamente como que o "programa" que rege a saúde e doença, mas também grande parte da personalidade humana; inventário este altamente disputado, em nome do novo mercado do bios. O que nos parece é que o cartesianismo, como pressuposto metodológico e como motivação de dominação desenfreada, associado ao aspecto mercantil, ambos objetificadores do humano e da natureza, estão sendo levados às últimas conseqüências. Tanto o seu sucesso quanto o seu fracasso tornam-se cada vez mais evidentes nas crises clamorosas em que vivemos no planeta, nas relações humanas, na Saúde, nas condições vitais. O cuidado e o futuro próximo passam a ser, neste contexto, temas urgentes.

\section{Ameaça à dignidade, cuidado de si e futuro}

Ao explorarmos o pensamento foucaultiano para uma investigação à luz da bioética, sobre a passagem do cuidado à produção farmacológica de $\mathrm{si}^{4}$, abordamos uma questão que nos parece imprescindível trazer à baila para o estabelecimento de uma discussão sobre a dignidade humana.

3 Quanto isso cf. PELIZZOLI: 2007, Carta à filha de minha neta.

4 Mil e Uma Gramas: Do CUIDAdo À PRODUÇÃo FARMACOLÓGICA DE SI. Trabalho de Conclusão de Curso apresentado ao Departamento de Filosofia e Ciências Humanas da Universidade Federal de Pernambuco, para obtenção do título de Especialista em Bioética, sob a orientação do Prof. Dr. Marcelo Pelizzoli. 
Trata-se da apreensão de si por si do sujeito humano, no decorrer das mudanças paradigmáticas/históricas, e as implicações diretas desse apreender-se, a partir da auto-percepção - o compreender-se subjetivamente e conhecer-se fisiologicamente em uma dimensão que se mistura.

Seguindo pistas do pensamento foucaultiano, percebemos que podemos tomar como índice que o cuidado de si foi tido na antiguidade como um exercício de apreensão de si por si, que trazia intrínseco ao hábito do cuidarse, o hábito do praticar-se - desde a análise dos sonhos como técnica de existência até a medicação salutar - therapeia soteriodes. Interessante, sobretudo, é perceber que Foucault constatou em tal apreensão de si por si, um tempo precioso que acomodava a idéia de um "desnível", como um momento ou uma maneira de acesso real ao interior capaz de apreender a si, um tipo de desvelamento da identidade, em que ela é duplicada; neste processo localizou o instante em que pode se suceder à especulação autêntica mais pertinente à apreensão de si, então, por $\mathrm{si}^{5}$. Dito de outra forma, o que Foucault resgatou de relevante foi uma das necessidades humanas mais autênticas - a do tempo necessário para o sujeito conceber a si subjetivamente e contemplar-se fisiologicamente para, assim, conceber-se integralmente e reconhecer-se partícipe dentre os demais que constituem seu meio; é assim que o sujeito dispõe-se pronto para relacionar-se eticamente com este meio, "antecedido" da experiência de relações consigo mesmo.

A importância da contribuição do pensamento foucaultiano à discussão ora proposta está na dura percepção de que um sujeito que se confunde consigo mesmo em sua "liberdade", ainda que por ingenuidade, pode não compreender a que, ou a quem, deva aplicar os tais direitos, ainda que a ele próprio, como humano que é, caiba reivindicá-los. Ao que se justifica a ilustração inicial com nossa provocação com "patentes e royalties" sobre o alfabeto da vida.

A esse propósito, retomemos o mesmo Artigo (XXVII/2) invocado para nossa provocação, em sua continuidade, e observemos a defesa de que "Toda pessoa tem o direito de participar livremente da vida cultural da comunidade, de fruir as artes e de participar do processo científico e de seus benefícios". Sobre esse parágrafo, cabe um questionamento sobre a legitimidade desse direito de participação livre e igualitária de usufruto, sobretudo, dos processos científicos e seus benefícios, ser válida diante de uma sociedade que se utiliza da educação para incutir um discurso doutrinário em consonância ao paradigma tecnocientífico totalizante - via mercado. Não obstante, lembramos, ainda, que no quesito educação, o Artigo XXVI/1 reza que "toda pessoa tem direito à instrução" e que "a instrução será orientada no sentido do pleno desenvolvimento da personalidade humana e do fortalecimento do respeito pelos direitos humanos e pelas

5 Cf. FOUCAULT: 2004; p. 553-555. 
liberdades fundamentais [e que esta] instrução promoverá a compreensão, a tolerância e a amizade entre todas as nações e grupos raciais ou religiosos, e coadjuvará as atividades das Nações Unidas em prol da manutenção da paz", e, ainda, que "os pais têm prioridade de direito na escolha do gênero de instrução que será ministrada a seus filhos". Mas, como pensar em reclamar tal "direito" diante dos moldes educacionais tecnocêntricos que permitem a promoção da perda da articulação ou dialética entre o conhecimento e a compreensão através da pré-compreensão, ou seja, a união de conhecimento objetivo e compressão (tal como saber e sabedoria), como etapa sine qua non para preceder e suceder o conhecimento instrumental e possibilitar ao ser humano o exercício da transcendência ${ }^{6}$ ? Numa época em que livros são substituídos por apostilas, educação presencial por bites à distância, consciência por informação de tablóide, e empresas líderes do mercado de transgênicos financiam projetos "para a distribuição de material didático e de publicações sobre agricultura e meio ambiente nas escolas públicas brasileiras"7?

Ora, propomos uma retomada de aspectos do pensamento foucaultiano, e posterior a ele em relação ao pensamento jonasiano, dentro do reconhecimento de Foucault a alguns exercícios ou hábitos pertencentes ao processo da sedimentação dessa ingenuidade e periculosidade contemporânea constatada, e justamente por isso, alertada por Jonas. Foucault conferiu a Epicteto, dentre os pensadores antigos, o mérito da mais alta elaboração filosófica do homem no seu apreender-se, como etapa necessária para um efetivo cuidar-se. Para Foucault, foi Epicteto quem primeiro fez um uso retórico do próprio argumento que fundamentou sua justificativa ao atribuir ao homem o dever de cuidar de si, em função do reconhecimento de que era ele mesmo - o homem, o único animal dotado da capacidade de servir-se como lhe conviesse, pois tinha a razão - uma armadilha que Zeus houvera delegado ao homem, dando-lhe o 'privilégiodever' e confiando-lhe o "dom-obrigação"8. É relevante acrescentar que o exercício pleno dessa faculdade, para Epicteto, dava-se na sua atuação do controle de outras faculdades, como o falar e o agir, mas que apesar da hierarquia entre tais faculdades, não havia qualquer distinção entre corpo e mente; a razão, portanto, respondia tanto pelo exercício cognitivo como pelo exercício físico - ou neurofisiológico - que àquela idade se entendia como

6 Cf. ARENDT apud MIRANDA: 2006; p. 19

7 "Em 2003 a empresa Monsanto lançou, como parte do seu projeto de responsabilidade social e com apoio do Ministério da Cultura, o projeto "O grão que conquistou o Brasil", distribuindo para os alunos de $5^{\mathrm{a}}$ à $8^{\mathrm{a}}$ séries, de 5.049 escolas da rede pública estadual da Bahia, Mato Grosso, Goiás, Rio Grande do Sul e Distrito Federal, além de fornecer a 500 educadores do ensino fundamental informações, material de apoio e cursos sobre dois dos assuntos de maior destaque da atualidade: agricultura e ambiente" (Cf. MIRANDA: 2006; Anexos).

8 Cf. FOUCAULT: 2007; p. 52-53 
unidade humana, e se revelava no exercício de conversar consigo ${ }^{9}$. Dessa elaboração, e da continuidade desse tipo de exercício ao longo dos tempos, seguiu-se o aprimoramento de um apreender-se que, à época de Sócrates, incorporou também o reconhecimento da importância da imaginação e da memória, até chegar à elaboração de um elo com o porvir. A importância do porvir para Foucault estava, relevantemente, intricada à imaginação e à memónia, não por um encadeamento, mas antes por uma aporia. Ele observou que no pensamento dos antigos não havia porvir na memória, assim como não havia memória no porvir e, embora no platonismo se tenha constatado a prática de olhar sobre si via memória, fica claro que, para Foucault, isso implicava apenas em um reconhecimento mnemônico ${ }^{10}$ - usado como acesso à verdade 'essencial' que conferiu, quando muito, um exercício de constatação ${ }^{11}$. Foi, então, depois do platonismo que ocorreu a mudança mais expressiva em relação à compreensão sobre o porvir: àquela dada no pensamento agostiniano, em que se passou a atribuir, ao exercício da memória, o sentido de uma prática meditativa. Outra mudança, de tamanha relevância, só viria no fim da Idade Média para o início da Idade Moderna, com a passagem do sentido da prática meditativa para o método cartesiano $^{12}$. Mas sobre o porvir, Foucault colocou ainda em xeque uma divergência entre epicuristas e estóicos. Ele observou que, enquanto para esses primeiros convinha "afastar as representações ou os pensamentos sobre o infortúnio", voltar-se ao "pensamento sobre os prazeres, e sobre todos os prazeres que possam um dia advir em nossa existência" - avocatio - e depois exercitar a "lembrança dos prazeres que outrora conhecemos" revocatio; para os outros, o olhar sobre si era compreendido como um exercício de provar-se enquanto sujeito da verdade, ou seja, um exercício de indagação ou questionamento - e aqui, observe-se que, duma visão hermenêutica, vêse um progresso no pensamento ocidental, haja vista que, antes, no platonismo, o exercício mais semelhante era realizado apenas no intuito de constatar ${ }^{13}$. Os estóicos eram adeptos à prática da premeditação ou presunção

9 Cf. FOUCAULT: 2004; p. 556

10 Como para Platão toda alma humana contemplava os seres verdadeiros quando estava no mundo supra-sensível, ao virem para o mundo sensível e habitarem um corpo, esquecia-se daquilo que viram anteriormente, e por isso, apenas algumas almas conseguiam contemplar através da reminiscência a verdadeira realidade das coisas (Cf. FANTINI, 2007). Daí, a mnemônica: tratava-se de uma techné voltada para o desenvolvimento de memorização através tanto do exercício pleno, como da exploração de artifícios, como a associação de idéias a outras idéias e/ou a fatos.

11 Cf. Foucault, 2004, p. 558, e antes p. 563-564.

12 Cf. p. 560-561. Entenda-se o cartesianismo aqui como um método analítico que consiste em decompor fenômenos complexos em elementos menores no intuito de compreender o todo a partir das partes, que tem como decorrência da sua filosofia uma visão de mundo pautada na certeza do conhecimento científico, sendo esta certeza, matemática em sua natureza essencial. Cf. Pelizzoli, 2007, cap. 6.

13 Cf. p. 568-569 e ante cf. p. 558 . 
dos males - praemeditatio malorum, a qual Foucault considerou como um concomitante exercício da morte e exame da consciência ${ }^{14}$ e, ainda, reconheceu a esta um valor específico para além da premeditação e presunção dos males, em função do uso seu da memória para saber distinguir entre um mau potencial e uma "peripécia", ou imprevisto. Para os estóicos, o homem sem disposição do discurso-socorro da memória tornar-se-ia "permeável" aos acontecimentos:

Com efeito, dizem os estóicos, um homem que se vê bruscamente surpreendido por um acontecimento corre o risco de encontrar-se em estado de fragilidade, tamanha a surpresa e o despreparo para este acontecimento. Este homem não tem a sua disposição o discurso-socorro, o discurso-recurso que lhe permitiria reagir como convém, não se deixar perturbar, permanecer mestre de si. E, na falta deste equipamento, ele será de certo modo permeável ao acontecimento. Este acontecimento vai entrar em sua alma, perturbá-la, afetá-la, etc. ${ }^{15}$

Ainda sobre o porvir, Foucault assinalou que outros pensadores, a exemplo de Sêneca, também viam com bons olhos o porvir. Sêneca defendia a idéia de que se limitar ao presente era o mesmo que se reduzir ao campo das satisfações; para ele, no porvir repousava a possibilidade de exercitar o enfrentamento do medo, para que quando este se desse, tivesse-se intimidade com a prática da "regra pior": "Qualquer que seja o mal, avalia-o em teu pensamento, faz o balanço de teus temores acerca dele: certamente compreenderás que o que te dá medo é sem importância e sem duração"16; embora, também alertasse sobre a "artimanha" do porvir nos prender pela esperança, e o passado - ou memória, pela lembrança - deferindo "a posse mais segura", portanto, a esta última ${ }^{17}$. Para Foucault, a importância mais expressiva da contribuição de Sêneca em seu estudo sobre o cuidado de si, parece mesmo repousar na dedicação deste, bem como na defesa à vigilância diária de si como exercício para viver bem ${ }^{18}$.

Ora, se partirmos dessa concepção de porvir, rumo ao estado proteofóbico ${ }^{19}$ que aureola hoje essa mesma sociedade ocidental que um dia o prezou como exercício, não é necessário grande esforço para percebermos que o que foi promovido em suas revoluções consecutivas, culminou em mudanças significativas sobre nós. A esse propósito, se relacionarmos, por

14 Ibid, p. 562.

15 Idem. Ibidem, p. 569.

16 SENECA apud FOUCAULT, 2004; p. 572.

17 Cf. Idem, p. 568.

18 Cf. FOUCAULT, 2007; p. 54.

19 Utilizamos o termo proteofobia na acepção difundida por Bauman (1997) para caracterizar o "[...] desagrado por situações nas quais a pessoa sente-se perdida, confusa e despotencializada", através da qual esse aborda a perda de controle sobre o espaço social quando "[...] não sabemos como continuar em certas situações porque as regras de conduta, que definem para nós o significado de 'saber continuar', não as cobrem" (Cf. p. 188). (Cf. MIRANDA; MONTEIRO TENÓRIO, 2007). 
exemplo, o porvir em tal acepção e prática proposta por Sêneca com a discussão sobre a educação que já introduzimos, cabe por demais a elaboração do conceito de "estado de cultura", colocado por Postman (1994) em Tecnopólio: a rendição da cultura à tecnologia. O estado de cultura foi um conceito elaborado por Postman para corporificar a deificação da tecnologia, promovida durante a passagem da tecnocracia (século XVIII, ou século da mecanização) para o tecnopólio (século XIX, ou século das invenções comerciais), à custa de uma superexposição rumo a um colapso "geral da tranqüilidade psíquica e do propósito social". Segundo esse autor, foi o estado de cultura que possibilitou o "amanhamento" necessário, a tal passagem, sob a égide de uma sonsa liberdade política e religiosa representadas como ícones culturais, que foram introduzidas mudamente no cerne da vida social, durante o período de transição. O estado de cultura figurou, pois, como uma "anestesia" que minimizou impactos, bem como, atenuou resistências à mudança proposta ${ }^{20}$.

Diante disso, o que dizer quanto ao Artigo XII que reza que "ninguém será sujeito a interferências na sua vida privada, na sua família, no seu lar ou na sua correspondência, nem a ataques à sua honra e reputação [e que] toda pessoa tem direito à proteção da lei contra tais interferências ou ataques"? Apesar de não termos uma resposta, ao menos encontramos um indício que, de alguma forma, já acena um movimento que compartilha nossa angústia: a semelhança entre o praemeditatio malorum e o princípio da precaução ${ }^{21}$, defendido pelo pensamento bioético e por Hans Jonas.

Retomando o porvir por nossa leitura foucaultiana, é em Plutarco - a quem Foucault atribuiu uma "ambivalência" entre do estoicismo e epicurismo, que percebemos uma visão que nos propicia a sensação de um presente etnográfico ${ }^{22}$ com relação ao porvir. Ora, foi Plutarco que viu uma distinção entre os homens voltados para o porvir, insensatos - anóetoi - e os

20 Cf. POSTMAN: 1994; p. 79-83.

21 Tal princípio ficou conhecido na Conferência RIO 92, no artigo 15 da sua Declaração. Sua definição básica: "é a garantia contra os riscos potenciais que, de acordo com o estado atual do conhecimento, não podem ser ainda identificados". Segundo este princípio, "na ausência da certeza científica formal, a existência de um risco de um dano sério ou irreversível, requer a implementação de medidas que possam prever este dano" (Cf. MIRANDA: 2005). Em todo caso, já em Hans Jonas encontramos essa acepção.

Z "Esse é um tempo verbal especial que tem como objetivo concentrar passado, presente e futuro num presente contínuo. Talvez nem sempre usado honestamente, o presente etnográfico tem mais mérito do que uma dimensão temporal reconstruída ou mal construída. Ele sintetiza, em um ponto no tempo, os eventos de muitos períodos, o valor da síntese estando na força da análise do tempo percebido. Supõe-se que o que quer que seja importante no passado se fará saber e sentir no aqui e agora. Idéias correntes sobre o futuro da mesma forma levam os juízos presentes por certas vias e bloqueiam outras. Ele supõe uma perspectiva de mão dupla em que 0 indivíduo trata seu passado seletivamente como fonte de mitos validantes e o futuro como o lugar dos sonhos. O tempo verbal se refere a um filtro de duas vias sendo usado no presente para retirar dos mitos e sonhos certos conjuntos que se engatem plausivelmente como guias para ação" (DOUGLAS; ISHERWOOD: 2006; p. 61) 
homens voltados para o passado e que fazem uso da lembrança, ou da memória, para em seu porvir - phrónimoi: o homem do porvir, uma vez não atento ao presente, não era capaz de totalizar a "vida social", pois, devorado pelo esquecimento, estava entregue à "descontinuidade"23.

Sobre Plutarco, Foucault assinalou que sua defesa ao exercício de um papel político como um ato social ${ }^{24}$ era cautelosa e recriminava o uso da política como atividade ocasional, porque esta, a política, deveria consistir de vida e prática e, portanto, ser fundamentada na razão. E aqui intercalamos, por última vez, o pensamento antigo com uma discussão à luz da acepção do princípio da autonomia contemporâneo, pois observamos que, da ótica da nossa investigação foucaultiana, o que vemos é uma defesa de Plutarco sobre a idéia de que a autonomia do sujeito não deveria ser embasada em seus interesses, mas, antes, nos interesses e objetivos da coesão social. Não obstante, isso nos remete diretamente a uma prática de si, em que para se livrar do risco da desgraça da descontinuidade, exigia-se um ponderado uso da autonomia de cada sujeito em particular. Se à autonomia cabia um uso individual, enquanto ao porvir cabia um efeito, ou uma prática social, à autonomia cabia também um cuidado de si por si, que inevitavelmente, imbricava-se ao porvir. Ora, a isso sim caberia a plenitude do Artigo XXII, de que "Toda pessoa, como membro da sociedade, tem direito à segurança social e à realização, pelo esforço nacional, pela cooperação internacional e de acordo com a organização e recursos de cada Estado, dos direitos econômicos, sociais e culturais indispensáveis à sua dignidade e ao livre desenvolvimento da sua personalidade".

Com efeito, uma leitura sobre as origens do cuidado de si vai muito além do abordado aqui. Na medida do possível, o que empreendemos é uma síntese, da maneira mais coerente possível, do que vimos de relevante nas concepções dos direitos ao exercício de uma dignidade humana resguardados na antiguidade da nossa sociedade - e por isso a escolha em fazê-lo pela via da leitura foucaultiana. Desse empreendimento, tomaremos como deferimento que, em sua origem, o cuidado de si no ocidente era dialógico tanto na relação do sujeito com o social, como na relação do corpo com a alma, tanto como no ínterim da relação de si para consigo mesmo. E, ainda, que o porvir figurava como uma preocupação do amanhã que deveria ser exercida no ontem, e que era por essa nessa noção "ubíqua" de tempo, que se responsabilizava o próprio sujeito pelo "cuidar-se" num presente contínuo. Vemos que o cuidado de si está, para Foucault, no exercício de uma hermenêutica do sujeito, desde a sua origem "atravessado pela presença do Outro: o outro como diretor da existência, o outro como correspondente a quem escrevemos e diante de quem nos medimos, o outro como amigo que

23 Cf. FOUCAULT, p. 566 e antes cf. 2004; p. 564-565.

24 Cf. FOUCAULT: 2007; p. 94. 
socorre, parente benfeitor" 25 , e que, portanto, tal exercício não constitui "uma exigência de solidão, mas uma verdadeira prática social" ${ }^{26}$, ao que procede:

Quaisquer que sejam estes exercícios, uma coisa merece ser observada, é que todos eles são praticados em referência a situações que o sujeito também poderá ter de afrontar: é, portanto, o indivíduo como sujeito da ação, de ação racional e moralmente admissível, que se trata de constituir. $O$ fato de que toda essa arte da vida esteja centrada em torno da questão da relação consigo não deve iludir: o tema da conversão a si não deve ser interpretado como uma deserção do âmbito da atividade, mas antes como a busca do que permite manter a relação de si para consigo como princípio, regra das relações com as coisas, com os acontecimentos e com o mundo ${ }^{27}$.

\section{Diretos Humanos?}

É importante percebermos a dependência da capacidade de abstração do sujeito que hoje requer direitos sobre sua humanidade estar mediada pela sua apreensão de si, mas, diante do cenário paradigmático em que nos encontramos, torna-se indispensável que o façamos em concomitância a uma reflexão crítica sob os moldes que geram a formação desse sujeito, uma vez que estes é que vão fomentar não apenas suas ações sobre si e seu meio, como também delegar para as gerações futuras o resultado de todo esse empreendimento ${ }^{28}$.

Há de nossa parte o crédito, tão meritório como indiscutível, à importância da elaboração da Declaração Universal dos Direitos Humanos em 10 de dezembro de 1948. Mas há também a percepção de que essa iniciativa se fundamentou sobre um alicerce estático, em decorrência de um evento ocorrido. Por isso, inda que seja clara a preocupação, em tal iniciativa, de transcender às circunstâncias e buscar o alcance de uma orientação pautada no conceito de um "presente etnográfico", o que percebemos é que tais direitos ora sofrem as conseqüências de não acompanharem o desenvolvimento do paradigma no qual ainda se acomoda. O alcance subjetivo do sujeito contemporâneo sobre os artifícios disponibilizados a ele, precisa de noções que lhe correspondam. Não é difícil hoje quando se fala em direitos humanos, que se acompanhe de sua abordagem, a discussão que o contrapõe aos conceitos do direito humanitário, que por vezes, estes nem mesmo se correspondam. Ao que sintetizamos com o seguinte fragmento emprestado do artigo de Michel Lotrowska, para a Campanha de Acesso a Medicamentos Essenciais de Médicos Sem Fronteiras:

É interessante avaliar até que ponto os conceitos do direito humanitário e a prática dos direitos humanos se cruzam. Os direitos humanos sempre

25 GROS apud FOUCAULT: 2004; p. 650.

26 Dossiê "Gouvernement de soi et des autres", apud FOUCAULT: 2004, p. 650.

27 Idem. Ibid.; p. 651.

28 Cf. JONAS: 2006, cap. 1. 
aparecem como uma meta de longo prazo que países e instituições tentam alcançar, sabendo que provavelmente nunca poderão atingir as metas sugeridas. Eles têm uma origem histórica bem localizada, e pressupostos de igualdade e individualidade claros, mas não são contextualizados no tempo e no espaço contemporâneo. Eles acabam sendo referências supranacionais que países deveriam atingir e respeitar, mas não o fazem porque a igualdade e individualidade não são princípios universalmente aceitos no mundo. Por outro lado o direito humanitário tem um lado prático imediato, contextualizado no campo das crises e visando o benefício imediato para a pessoa, e sobretudo o grupo em risco de vida ${ }^{29}$.

Sobre discussões éticas em relação a tais dimensões, o que constatamos é que a urgência da necessidade de uma nova estrutura filosófica para lidar com essa realidade é tão ampla em sua perspectiva como transdisciplinar em sua origem. E aqui, mais uma vez cabe lembrar de Hans Jonas, com seu novo princípio fundamentador da vida ética pela responsabilidade coletiva. Constamos também - e a olhos nus, que não cabe a tal necessidade uma reclamação estritamente moral, assim como o é a Declaração Universal dos Direitos Humanos. Dessa forma, o que percebemos é antes a necessidade de um resgate da dignidade humana, ou dito de outra forma, um resgate do processo de apreensão de si que possibilite ao sujeito contemporâneo seu cuidar-se integralmente, seja frente às expectativas do progresso tecnocientífico, seja frente aos moldes ideológicos - ora propostos, ora impostos, que lhe ameaçam constantemente com a perda de sua autonomia humana. Nesse contexto, a proposta da adoção do pensamento e prática bioética através da instauração de um paradigma que o corresponda é o que vislumbramos como alternativa para o processo, ora percebido como necessário, para que a partir deste se pense em sua garantia. Não obstante, para propor o meio mais coerente para o exercício pleno da dignidade humana, precisamos igualmente fazer o caminho inverso da doutrina totalizante de mercado, a que ora somos impelidos, e retomar o do processo entre o conhecimento e a compreensão (saber e sabedoria) que, inelutavelmente, nos pertence, e ao que preza o Artigo I da Declaração Universal dos Direitos Humanos: "Todas as pessoas nascem livres e iguais em dignidade e direitos. São dotadas de razão e consciência e devem agir em relação umas às outras com espírito de fraternidade". E é nesse espírito que se intercala exemplarmente o pensamento de Jonas, incluindo agora também aquilo que a esta Declaração ficou mascarado, as condições ambientais e também a dignidade dos seres não-humanos ${ }^{30}$.

\section{Do cuidado de si à responsabilidade pelo futuro em $\mathrm{H}$. Jonas}

A passagem de Foucault para H. Jonas é complementar nesta discussão, e mostra uma motivação eminentemente ético-prática, que une cuidado de

20 LOTROWSKA, 2006.

30 Não aprofundaremos aqui a Ética Animal. Para isso recomendamos as obras de Carlos Naconecy e de Peter Singer. 
si e ética da responsabilidade em tempos de urgência bioética. Também e exemplarmente Jonas está preocupado em conter a força do deus-homem Prometeu, desacorrentado e descontrolado, como é a tecnociência e economia sem limites, e o que isso pode acarretar para o futuro próximo. Esta preocupação parte do fato do vazio e relativismo ético reinantes na (des)ordem do atual modelo de Poder, e que exige compor novas formas de imputar o dever e os princípios orientadores que assegurem a humanidade; é isso que ele chama de "heurística do temor", modus de prevenção onde "somente a previsível desfiguração do homem nos ajuda a alcançar aquele conceito de homem que há de ser preservado de tais perigos" ${ }^{31}$. Aqui entra o alerta quanto à liberdade do ser humano, na medida em que a "dinâmica tecnológica de progresso, que é de escala planetária, alberga enquanto tal um utopismo implícito", ou seja, construção de um mundo fantasioso e artificial; é por isso que "o princípio de responsabilidade contrapõe uma tarefa mais modesta, decretada pelo temor e o respeito: preservar a permanente ambigüidade da liberdade do homem... preservar a integridade de seu mundo e de sua essência frente aos abusos do poder"32.

\section{A tecnologia como "vocação" da humanidade e o novo imperativo}

O princípio responsabilidade de Jonas é enfático ao mostrar que o homo faber (cerne da técnica, mas depois por ela de algum modo ele é subjugado!) se pôs muito acima do homo sapiens, do homem da inteligência e do bom senso. É como se o "feitiço virasse contra o feiticeiro", na medida em que o agir individual no mundo técnico é quase apagado no coletivo; e o que passa a nos mover emocionalmente é uma espécie de utopismo paradoxalmente conservador e dominador. "Hoje a técnica se transformou em um infinito impulso para adiante da espécie..., em cujo contínuo progresso que se supera a si mesmo para coisas cada vez maiores se tenta ver a missão da humanidade..."33. E o fato de que o agir coletivo e a definição de ser humano, dada cada vez mais por seus papeis e lugar no Sistema, exigem uma nova forma de pensamento e de ação, baseada em novos imperativos éticos. Devese levar em conta aqui o que implica o caráter modificado da ação humana hoje, ou seja, sua amplitude, complexidade, sobre o próprio agente, não apenas em relação ao mundo natural.

"Que sempre no futuro deva haver mundo como tal - apto para que o homem o habite... (é o) axioma geral... como obrigação prática para com a posteridade de um futuro distante e como princípio de decisão para a ação presente, (...) (trata-se da)... obrigação de garantir no futuro a premissa

31 JONAS: 1995; p. 16. "Agora balançamos diante da desnudez de um niilismo no qual um poder máximo vai emparelhado com um máximo vazio, e uma máxima capacidade vai emparelhada com um mínimo de saber sobre ela."

32 Idem, p. 16-17.

33 Idem, p. 36. "Se a esfera da produção invadiu o espaço da ação essencial, a moral terá que invadir a esfera da produção... e terá de fazê-lo na forma da política pública." (Idem, p. 37). 
primeira de toda obrigação, isto é, justamente a existência de candidatos a um universo moral no mundo físico" ${ }^{34}$. Esta argumentação é muito significativa, na medida em que apresenta a manutenção de um futuro equilibrado socioambientalmente devido primeiro ao "obrigativo" de que deve existir pessoas, o que implica em que estas possam e devam realizar a ética, e se pensarmos que também aquela ética visará o futuro, o obrigativo justifica-se pela continuação permanente da espécie humana como sentido primeiro e mais forte. Por conseguinte, o novo imperativo apresenta-se assim: "Obra de tal modo que os efeitos de tua ação sejam compatíveis com a permanência de uma vida humana autêntica na Terra". Ou, "não ponhas em perigo as condições da continuidade indefinida da humanidade na Terra"... ${ }^{35}$ Segundo este, é passível a uma pessoa até arriscar e danar sua própria vida, mas de forma nenhuma e sob nenhuma alegação o poderá fazê-lo em relação à vida da humanidade e ao futuro desta. Se por um lado o imperativo de Jonas pode ser arrojado, por outro lado ele visa às conseqüências reais e objetivas da (i)responsabilidade das ações e empreendimentos atuais. É por isso que para ele, os efeitos últimos, remotos e os epifenômenos devem ser incluídos, pois eles já vêm acontecendo ${ }^{36}$. $\mathrm{Na}$ verdade o imperativo é simples por um lado, diz que devemos pensar antes nos efeitos possíveis, nas crianças e nas gerações que vão vir, que em geral colhem os frutos de nossas ações negativas atuais, e a grande ameaça é que ocorram transformações irreversíveis.

Basicamente, a vocação e o utopismo denunciados por Jonas é o que ele chama de "escatologia secularizada", a saber, uma perspectiva míticohistórica de um mundo (Natureza) totalmente diferente e transformado, futurístico idealizado, que passa a habitar o próprio mundo laico (não religioso), tal como os feitos do moderno progresso tecnológico, onde "surge a possibilidade de conceber todo o anterior como passo prévio para o atual, e todo o atual como passo prévio para o futuro"; daí a escatologia secularizada a "estabelecer já na Terra o reino dos céus".

\section{O homem como objeto da técnica}

Ponto importantíssimo analisado por Jonas é sobre os efeitos desta techne (técnica...) aplicados não só à natureza e ao ambiente externo, mas ao ser humano e sua essência, quando ele se vê como objeto da técnica. O primeiro caso analisado por ele é o do prolongamento da vida. Hoje, com os progressos da citologia e manipulação genética, se intervém já na continuação e alargamento do prazo de vida; ou seja, a própria mortalidade humana, seu

34 Idem, p. 38.

36 Idem, p. 41.

36 Aponto o caso das doenças degenerativas (câncer em especial) por exemplo, que são nitidamente de caráter ambiental, da alimentação, qualidade do ar, estresse, cigarros, bebidas, insumos e aditivos químicos. Uma em cada quatro pessoas terá câncer (dados dos EUA)!!! 
tempo "natural" de vida, é alterada e poucos se perguntam se isso não é contrário à sabedoria superior da Natureza e da relação entre as espécies e o ecossistema em seu longo processo. Agora, surge também a hipotética questão do "quanto tempo vou querer viver"? Isso traz grandes implicações éticas, no próprio processo de sucessão das gerações e da velhice ${ }^{37}$. "A morte aparece já não como algo necessário, consubstancial à natureza dos seres vivos, senão como uma falha orgânica evitável, ou pelo menos tratável e deslocável por largo tempo. Até que ponto isto é desejável?"38 Reclama o autor, afirmando que, originalmente, o ter de morrer é algo ligado instrinsecamente ao fato do haver nascido.

O segundo caso é o do "controle da conduta" humana. Será que não estamos sendo encaminhados, agora mais ainda devido aos acontecimentos de recrudescimento do imperialismo (e de terrorismo) dos EUA, para a sociedade do controle total, a sociedade do "1984" de George Orwell, onde o Grande Olho tudo vê e domina, ou então levados a uma nova Laranja Mecânica mais sofisticada, do filme de Stanley Kubric? "As velhas categorias éticas... não estão equipadas para julgar sobre o controle da mente mediante agentes químicos ou influxos elétricos diretos sobre o cérebro por implantação de eletrodos... É imperceptível o passo que leva do aliviar o paciente... a aliviar a sociedade do incômodo provocado por comportamentos individuais difíceis entre seus membros." 39

O terceiro caso é o mais complexo, o da manipulação genética, e Jonas nega-se a tratar dele por ser não apenas o mais perigoso e menos simples, mas por ser muito extenso. Todavia, ele nos deixa a intrigante e perspicaz pergunta, diante das possibilidades de modificação genética de seres humanos: "Quem serão os escultores desta imagem (homo faber) segundo quais modelos e sobre a base de quais conhecimentos? Aqui se coloca também a questão do direito de experimentar com seres humanos" (idem, 54). São grandes desafios de âmbito da Bioética, como ética de vida que busca tomar posturas claras diante do que estamos passando.

\section{Heurística do temor e responsabilidade da ciência}

Como se pode ver, a posição de Jonas envolve questões político-práticas de primeira ordem, e que não se trata, segundo ele, de apenas cultivar "sentimentos" éticos subjetivos, mas de uma "justificação teórica no princípio racional", onde mesmo se for o caso da fé, esta deverá ser uma "fé bem

3 Cf. idem, p. 49.

38 JONAS, 50. "Tomemos o caso extremo: se suprimimos a morte suprimiremos a procriação, pois esta é uma resposta da vida à morte. E a juventude...? A maior acumulação de experiência prolongada não substitui essas coisas; não pode recuperar o singular privilégio de contemplar o mundo pela primeira vez com olhos novos, nunca reviver o assombro... curiosidade da criança, o que desfalece no adulto e que raras vezes se converte em afã de conhecimento." (p. 51)

39 Idem, p. 52. 
fundamentada" ${ }^{40}$. Neste sentido, a heurística do temor já é ponto de partida suficiente para mover pesquisas científicas e precauções sociais e políticas quanto aos efeitos remotos, para preservar o homem da desfiguração de sua humanidade. Aqui, o que está em jogo é não menos que o próprio ser humano, em sua essência. E, sendo que o mal chama mais a atenção do que o bem, e é de conhecimento mais fácil, "a mera presença do mal nos impõe seu conhecimento...", pois, sabemos melhor e antes o que não queremos do que o que queremos ${ }^{41}$.

Sem dúvida, pensamos que pode ser perigosa tal estratégia do medo, no sentido de cairmos no sobrevivencialismo, na busca de salvação individual, efeito colateral da pedagogia da catástrofe que ameaça a heurística do temor, no sentido de amarrar as mãos das pessoas e torná-las indiferentes ou defensivas ao mal sem voltar-se para a ação. Não obstante, Jonas alerta que o temor que ele prega não pode ser "patológico", como um modelo hobbesiano para assustar, mas um "temor de caráter espiritual", como sentimento apropriado ao que está ocorrendo ${ }^{42}$.

Devido à insegurança das projeções sobre o futuro, à complexidade dos efeitos nos ecossistemas, a insondabilidade e impredizibilidade do progresso e seus inventos, o saber e a ciência devem esforçar-se ainda mais; mas não só, é preciso também considerar seriamente o simples saber acerca das possibilidades (ameaças) como "perfeitamente suficiente para os fins da casuística heurística que se coloca à serviço dos princípios éticos". Daí que os prognósticos maus devem prevalecer sobre os bons na hora de tomar decisões e nos grandiosos empreendimentos da tecnologia moderna ${ }^{43}$.

\section{Concluindo: sobre a fundamentação do dever para com o futuro em tempos de cuidado}

“... postergar... quem sabe será demasiado tarde."

Percebemos que pensadores contemporâneos, tais como Foucault e Jonas, inserem-se cada vez mais nos embates éticos gerados pela atual crise e alteração essencial, social e ambiental. São muito atuais e têm um diagnóstico muito lúcido na questão da dignidade humana e liberdades ameaçadas. Em Jonas é evidente a opção por uma ética global, ambiental e para as novas gerações, o que de Foucault percebemos indiretamente.

40 Cf. idem, p. 63.

41 Cf. idem, p. 65.

4 Cf. idem, p. 67.

43 Os quais, "não são nem pacientes nem lentos, (mas) comprimem... os múltiplos e diminutos passos da evolução natural em poucas e colossais arrancadas, renunciando assim à vantagem, asseguradora da vida, de uma natureza que caminha suavemente". Cf. Idem, p. 71-72 e, antes, idem p. 68.

4 Idem, p. 70. 
Igualmente, a opção pela não reciprocidade/igualdade entre seres humanos na ética, e a gratuidade e obrigação da ação efetiva por e para outrem aspectos presentes em Levinas. No caso de Jonas, trata-se em especial do Outro que está para nascer, e que não está aqui para rogar por si e por um ambiente salutar, outrem desconhecido. "Em primeiro lugar é preciso dizer que o que temos de exigir a nosso princípio não pode ser-nos proporcionado pela idéia tradicional de direitos e deveres; esta idéia se funda, com efeito, na reciprocidade" 45 . O "dever para com os descendentes" é muito profundo, apesar de ser pouco pensado; e ele se assemelha ao que a ética tradicional e das pessoas em geral aponta no caso do dever para com os filhos, da mãe em especial, um dever não-recíproco e com desgaste de si pelo outro ${ }^{46}$.

Enfatizando a prioridade do "dever para com a existência", como dever coletivo e de preservar a essência humana aceitável e não manipulada, Jonas afirma que "impossibilitar o dever dos homens posteriores, isto é o autêntico crime... Isto quer dizer que temos de velar não tanto pelo direito dos homens futuros - seu direito à felicidade... quanto por seu dever, por seu dever de conformar a autêntica humanidade..." 47 . Este dever deverá ser o patamar para todo o direito e dever individual, tal como a ética ecológica global prega hoje, do "agir local e pensar global".

Assim, inspirados em Jonas, mas também em Foucault, podemos retomar coerentemente as grandes perguntas sobre o sentido da vida humana, a morte, o tempo, o ser, a existência humana, os valores e princípios. Urge tomar posturas diante do avanço das fronteiras da Vida pela biotecnologia e mercado vigentes e seus descompromissos socioambientais, em especial para com o futuro. É nesta motivação que Jonas vai afirmar que é preferível a vida boa e equilibrada do que o reino da destruição, do relativismo e do niilismo atuais; é preciso preferir o ser ao não-ser. No fundo está a questão do valor da vida e de sua manutenção, e a ética como um princípio fundamental e constituidor do próprio sentido de ser do humano, como na ética da alteridade, mas buscando um modus objetivo de normatividade e agir ${ }^{48}$. Aqui, já nos postamos em um outro âmbito: o do cuidado, que como "cuidado de si", abrange naturalmente o cuidado socioambiental e transgeracional.

45 Idem, p. 82.

46 "Este é o arquétipo de toda ação responsável, arquétipo que, felizmente, não precisa de nenhuma dedução a partir de um princípio, senão que se encontra poderosamente implantado pela natureza em nós..." (Idem, p. 83).

47 Idem, p. 86.

48 "Por isto será de vital importância determinar o status ontológico e epistemológico do valor e examinar a questão de sua objetividade." "...somente de sua objetividade seria dedutível um dever-ser objetivo e, com ele, uma vinculante obrigação de preservar o ser, uma responsabilidade para com o ser." (Idem, p. 96-97). 


\section{Referências}

DOUGLAS, M.; ISHERWOOD, B. O mundo dos bens - para uma antropologia do consumo. Rio de Janeiro: Editora da UFRJ, 2006.

FERREIRA, J. O Alfabeto da Vida (Da Reprodução à Produção). Lua Nova Revista de Cultura e Política, São Paulo, n. 55-56, p. 219-240, 2003.

FONSECA, F. Hans Jonas: (Bio)ética e crítica à tecnociência. Recife: Ed. da UFPE, 2007.

FOUCAULT, M. A hermenêutica do sujeito; edição estabelecida sob a direção de François Ewald e Alessandro Fontana, por Frédéric Gros. São Paulo: Martins, 2004.

. História da sexualidade 3: o cuidado de si. Rio de Janeiro: Edições Graal, 2007.

JONAS, H. O princípio responsabilidade - Ensaio para uma ética tecnológica. Rio de Janeiro: Contraponto/Ed. PUC-Rio, 2006.

JONAS, H. El Principio responsabilidad. Barcelona: Herder, 1995.

LOTROWSKA, M. 2006. Campanha de acesso a medicamentos essenciais de médicos sem fronteiras - medicalização da vida e direitos humanos. Disponível em: < http://www. bomdiariopreto.com.br/index.asp?jbd=1\&id=240\&mat=99661>

MARTINS, P. H. Contra a desumanização da medicina. Petrópolis: Vozes, 2003.

MIRANDA, E. Do paradigma tecnocientífico ao paradigma bioético: as propostas das novas configurações contemporâneas - o exemplo da lei de biossegurança (11.105/05). Recife, 2006. Monografia, UFPE/CFCH/Dep. de Ciências Sociais. Em: <http://www.id.ufpe.br/teses_ dissertacoes_monografias/Monografia\%20Erliane\%20Miranda.pdf>

. Mil e uma gramas: do cuidado à produção farmacológica de si. Recife, 2008. Monografia (Especialização), UFPE/CFCH/Dep. de Filosofia; CCB/Centro de Ciências da Saúde.

PELIZZOLI, M. L. Correntes da ética ambiental. Petrópolis: Vozes, 2003.

. A emergência do paradigma ecológico. Petrópolis: Vozes, 1999.

. Levinas: a reconstrução da subjetividade. EDIPUCRS, 2002.

. (Org.). Bioética como novo paradigma. Petrópolis: Vozes, 2007.

. "Utopia tecnocêntrica × Utopia ecológica". Revista Gaia (UFPB), v. 1, n. 2, mar. 2008.

Em: http://www.prodema.ufpb.br/revistagaia

POSTMAN, N. Tecnopólio: a rendição da cultura à tecnologia. São Paulo: Nobel, 1994.

TENNER, E. A vingança da tecnologia. São Paulo: Ed. Campus, 1997. 